\title{
Pattern of healthcare resource utilization and direct costs associated with manic episodes in Spain
}

\author{
Monica Tafalla*1, Luis Salvador-Carulla22, Jerónimo Saiz-Ruiz²,4, Teresa Diez¹ and Luis Cordero
}

\begin{abstract}
Background: Although some studies indicate that bipolar disorder causes high health care resources consumption, no study is available addressing a cost estimation of bipolar disorder in Spain. The aim of this observational study was to evaluate healthcare resource utilization and the associated direct cost in patients with manic episodes in the Spanish setting.

Methods: Retrospective descriptive study was carried out in a consecutive sample of patients with a DSM-IV diagnosis of bipolar type I disorder with or without psychotic symptoms, aged 18 years or older, and who were having an active manic episode at the time of inclusion. Information regarding the current manic episode was collected retrospectively from the medical record and patient interview.

Results: Seven hundred and eighty-four evaluable patients, recruited by 182 psychiatrists, were included in the study. The direct cost associated with healthcare resource utilization during the manic episode was high, with a mean cost of nearly $€ 4,500$ per patient, of which approximately $55 \%$ corresponded to the cost of hospitalization, $30 \%$ to the cost of psychopharmacological treatment and $10 \%$ to the cost of specialized care.

Conclusions: Our results show the high cost of management of the patient with a manic episode, which is mainly due to hospitalizations. In this regard, any intervention on the management of the manic patient that could reduce the need for hospitalization would have a significant impact on the costs of the disease.
\end{abstract}

\section{Background}

Bipolar disorder is a mood disorder characterized by extreme mood swings that cause recurrent episodes of mania or hypomania and depression [1]. Historically, it was called "circular madness" and "manic-depressive psychosis". According to DSM-IV-TR, two major categories of bipolar disorder exist: bipolar I disorder, in which patients have had at least one episode of mania, some have had previous depressive episodes, and most will have subsequent manic, depressive, hypomanic or mixed episodes; and bipolar II disorder, in which patients exhibit or have a history of major depressive episodes and hypomanic, but not manic, episodes [2].

In Europe, the estimated annual prevalence of bipolar disorder ranges from 0.2 to $1.1 \%$ with a median of $0.9 \%$,

\footnotetext{
* Correspondence: monica.tafalla@astrazeneca.com

1 Medical Department, AstraZeneca, Madrid, Spain

Full list of author information is available at the end of the article
}

i.e., 2.4 million people are affected by the disorder [3]. In Spain, using data on lithium consumption, the prevalence of bipolar I disorder has been estimated at 70 cases per 100,000 inhabitants [4], a figure that, because of the method used, underestimates the true prevalence of the disorder. Bipolar disorder is not only common, but is also an important cause of disability; it exhibits frequent psychiatric comorbidity, is associated with a high frequency of suicide, has a large impact on the functioning and wellbeing of the individual, and places a considerable economic burden on the individual and society [5-13].

According to the World Health Organization, bipolar disorder is the sixth leading cause of disability worldwide among persons aged 15 to 44 years [5], and the third among mental illnesses (after major depression and schizophrenia). The data provided by this organization in 2005 attributed more than thirty percent of all years lived with disability to neuropsychiatric disorders [6]. In addi- 
tion, patients with bipolar disorder have high psychiatric and medical comorbidity; in studies conducted in Europe, nearly all patients with bipolar I disorder had a history of having suffered another axis I disorder in their lifetime, more than two thirds had a history of one or more anxiety disorders and $70 \%$ had a history of a substance abuse disorder [7]. The lifelong risk of suicide in bipolar disorder is up to 20 times higher than in the general population [8-10]. Several studies have shown that even in less symptomatic patients (i.e. sub-threshold symptoms present), bipolar disorder causes a significant impairment of the functioning and well-being of the individual [11-13].

The studies conducted to date have identified high resource utilization and costs in bipolar disorders that were the highest among psychiatric disorders [14,15]. A prevalence cost study conducted in the USA estimated that the total cost of bipolar disorder in 1991 was $\$ 45$ billion [16]. Another study on incident cases in 1998 estimated the lifetime cost of bipolar disorder at $\$ 24$ billion [17]. Another study has recently been published in which the treatment costs of bipolar disorder in the USA in 2002 were estimated. The results were $\$ 12,797$ and $\$ 6,581$ for the mean charge and reimbursement per patient-year, respectively. In this study, 33\% of the treatment cost was attributed to bipolar disorder and the remaining $67 \%$ to associated comorbidity [18]. In Australia, the excess cost of bipolar disorder in 2004 was estimated at US\$4-5 billion [19].

In Europe, only four studies have assessed the cost of bipolar disorder [15]: two in France focusing on manic episodes [20,21], one in the Netherlands [22] and another in the United Kingdom [23], these last two focusing on bipolar disorder. The results differ greatly between the European and US studies; in the UK study, direct costs were estimated at approximately $€ 285$ million, compared to the equivalent of $€ 3$ billion in the USA [16]. The differences between the studies in Europe are also large with, for instance, direct costs that range from $€ 700$ to $€ 24,000$ per patient depending on the study [20-23]. These differences reflect differences in the management of the disease (mostly rates and duration of hospitalization) as well as the different perspectives in research question and methodologies.

No study is available on the costs of bipolar disorder in Spain. Very recently published data from a subsample of a pan-European study indicate that bipolar disorder causes high healthcare resource utilization in the Spanish setting, although no cost estimate was provided [24]. In another estimate of the cost of disorders of the brain in Europe [25], it was shown that bipolar disorder is the mental disorder generating the highest costs in Spain (5,807 €PPP 2004 (Purchasing power parity) per patient versus 5,082 for schizophrenia and 3,445 for depression).
The aim of the present study was to evaluate healthcare resource utilization and the associated direct cost in patients with manic episodes in our setting.

\section{Methods}

An observational study with retrospective data collection was carried out in a sample formed by consecutive patients with a DSM-IV diagnosis of bipolar type I disorder with or without psychotic symptoms visiting psychiatrist outpatient offices in Spain. The selected patients were aged 18 years or older, were having an active manic episode at the time of inclusion and were in contact with specialized care (public or private) for this reason in Spain during the reference period of April 2005 to March 2006.

Patients could be included at any time during the course of a manic episode, and information regarding the period between the onset of symptoms of that episode to the time of inclusion was collected retrospectively at the recruitment moment. A second phase of data collection was performed when the episode had ended. A maximun period of four months was defined in the protocol as sufficient for complete remission of the episode, and patients with no remission at four months were no longer followed. The study was carried out under real-world clinical practice conditions in an outpatient setting and information was collected in a case report form designed for this purpose.

The study was evaluated and approved by the ethics committee of Hospital Clínico San Carlos de Madrid and carried out in accordance with the ethical recommendations for clinical research contained in the Declaration of Helsinki and Good Clinical Practice guidelines. Written informed consent was obtained from all patients prior to their inclusion in the study.

Information was collected on each patient characteristics (sociodemographics, personal and family medical history), disease characteristics (duration of compatible symptoms, diagnosis, previous episodes) and current episode characteristics. All healthcare resources consumed during the current episode (drugs, outpatient and hospital care) were recorded using the medical history and patient interview as sources of data. The evaluator made a judgment about the relationship of each resource consumed with the patient's disease. Information was also collected on the existence of any legal or judicial problems during the manic episode, although their costs were not estimated.

The unit costs assigned to the healthcare resource utilization recorded for each patient were obtained from a healthcare unit costs database [26]. These unit costs were then updated to the year 2007 according to the corresponding inflation rate, $12.5 \%$ [27]. In addition, the costs of psychologist visits and group psychotherapy were 
obtained by calculating the average value of the fee lists published by several official psychologists' associations on the minimum cost of a patient visit. Finally, the cost of prescription drugs was obtained from the retail price of each individual drug including VAT published by the General Board of the Spanish Association of Official Pharmacists [28]. The cost per mg was then calculated to assign the actual cost of the drug to the dose prescribed and treatment duration in each patient. A list of all costs, expressed in 2007 Euros, is shown in Table 1.

Statistical analysis was performed by describing demographic variables, patient disease and resource utilization. Quantitative variables (e.g., age, disease duration, absolute frequency of resource utilization) were described by their mean values and standard deviations. Categorical variables (e.g., gender, comorbidity, presence of a specific number of hospitalizations or other resource utilization) were described by their absolute and relative frequencies.

In addition, to evaluate how sociodemographic or clinical characteristics affected resource utilization, exploratory bivariate analyses were used to compare resource utilization according to the values that could be taken by the different variables. To evaluate the significance of the difference, Student's $t$ test or the Wilcoxon signed rank test was used for quantitative variables and the chi- squared test for Fisher's exact test for categorical variables. All statistical tests were two-tailed and were considered significant if $\mathrm{p}<0.05$. Due to the exploratory nature of these analyses, no correction for multiple comparisons was used.

\section{Results}

Nine hundred and ten patients, evaluated by 182 psychiatrists, were included in the study. Of these, 126 patients' data were considered non-evaluable because of missing or inconsistent values and then excluded from the data base.

Demographic characteristics of evaluable patients are shown in Table 2. Most patients lived with their partner and were employed, although a substantial percentage (21.3\%) were on disability leave. Most of the sample lived in small urban areas with populations between 10,000 and 100,000 or medium-sized urban areas with populations between 100,000 and 1,000,000.

Clinical characteristics of the patients are described in Table 3. The first professional consulted by patients for the initial episode was the psychiatrist in the majority of cases, and this episode required hospital admission in $23.6 \%$ of cases. Only $4.1 \%$ of patients were newly diagnosed. In the twelve months prior to the current episode,

Table 1: Unit cost per healthcare resource used and source of estimate

\begin{tabular}{|c|c|c|}
\hline Resource & Source of estimate & Cost $(€, 2007)$ \\
\hline \multicolumn{3}{|l|}{ Hospitalization } \\
\hline Psychiatric hospital stay/day & Soikos (2004) \& INE (2007) & 240.27 \\
\hline \multicolumn{3}{|l|}{ Primary care } \\
\hline Primary care physician visit & Soikos (2004) \& INE (2007) & 15.67 \\
\hline $\begin{array}{l}\text { Community-based visiting nurse } \\
\text { service }\end{array}$ & Soikos (2004) \& INE (2007) & 15.65 \\
\hline Lithium determination & Soikos (2004) \& INE (2007) & 9.02 \\
\hline Group psychotherapy & $\begin{array}{c}\text { Official Psychologist Associations of } \\
\text { Cataluña, Castilla la Mancha, Cantabria, Las } \\
\text { Palmas, Barcelona }\end{array}$ & 24.86 \\
\hline Outpatient emergency dept. visit & Soikos (2004) \& INE (2007) & 110.94 \\
\hline \multicolumn{3}{|l|}{ Specialized care } \\
\hline Psychiatrist visit & Soikos (2004) \& INE (2007) & 39.99 \\
\hline Nonpyschiatric specialist visit & Soikos (2004) \& INE (2007) & 79.46 \\
\hline Psychologist visit & $\begin{array}{c}\text { Official Psychologist Associations of } \\
\text { Cataluña, Castilla la Mancha, Cantabria, Las } \\
\text { Palmas, Barcelona }\end{array}$ & 50 \\
\hline Hospital emergency dept. visit & Soikos (2004) \& INE (2007) & 120.21 \\
\hline
\end{tabular}


Table 2: Demographic characteristics

\begin{tabular}{|c|c|c|}
\hline Characteristic & $\mathbf{N}$ & \\
\hline Gender, n (\%) & 761 & \\
\hline Male & & $343(45.2)$ \\
\hline Female & & $418(54.8)$ \\
\hline \multicolumn{3}{|l|}{ Age, years, mean $\pm S D$} \\
\hline Total & 761 & $43.5 \pm 12.1$ \\
\hline Male & 343 & $41.9 \pm 12.2$ \\
\hline Female & 418 & $44.8 \pm 11.8$ \\
\hline Educational status, n (\%) & 784 & \\
\hline No studies & & $73(9.3)$ \\
\hline Primary school & & $340(43.4)$ \\
\hline Secondary school & & $256(32.6)$ \\
\hline University & & $115(14.7)$ \\
\hline Marital status, n (\%) & 762 & \\
\hline Married or cohabiting & & $337(44.2)$ \\
\hline Previously married & & $136(17.9)$ \\
\hline Never married & & $289(37.9)$ \\
\hline Employment status, n (\%) & 762 & \\
\hline Paid employment & & $202(26.5)$ \\
\hline Unemployed & & $81(10.6)$ \\
\hline Retired & & $81(10.6)$ \\
\hline Housewife & & $130(17.1)$ \\
\hline Student & & $24(3.1)$ \\
\hline Sick leave & & $66(8.7)$ \\
\hline Work disability & & $162(21.3)$ \\
\hline Other & & $16(2.1)$ \\
\hline Area of residence, $\mathrm{n}(\%)$ & 760 & \\
\hline Rural & & $156(20.5)$ \\
\hline Small urban & & $259(34.1)$ \\
\hline Medium urban & & $255(33.6)$ \\
\hline Large urban & & $90(11.8)$ \\
\hline Living situation, n (\%) & 779 & \\
\hline Lives alone & & $98(12.6)$ \\
\hline Lives with someone & & $681(87.4)$ \\
\hline
\end{tabular}


Table 3: Clinical characteristics

\begin{tabular}{|c|c|c|}
\hline Characteristic & $\mathbf{N}$ & \\
\hline \multicolumn{3}{|l|}{ First episode } \\
\hline Age at onset of $B D$, years, mean $\pm S D$ & 737 & $29.0 \pm 10.3$ \\
\hline First manic/mixed episode, $\mathrm{n}(\%)$ & 748 & $479(64.0)$ \\
\hline $\begin{array}{l}\text { Time since first episode at diagnosis, } \\
\text { years, mean } \pm \text { SD }\end{array}$ & 734 & $2.4 \pm 5.6$ \\
\hline \multicolumn{3}{|l|}{$\begin{array}{l}\text { Type of first contact with healthcare } \\
\text { sector, } \mathrm{n}(\%)\end{array}$} \\
\hline Psychiatrist & & $300(41.5)$ \\
\hline Hospitalization & & $171(23.6)$ \\
\hline Primary care & & $140(19.3)$ \\
\hline Emergency department & 724 & $72(9.9)$ \\
\hline Other & & $41(5.7)$ \\
\hline \multicolumn{3}{|l|}{ Current episode } \\
\hline Total duration, days, mean \pm SD & 708 & $76.4 \pm 43.0$ \\
\hline $\begin{array}{l}\text { Clinical status prior to current } \\
\text { episode, } \mathrm{n}(\%)\end{array}$ & 741 & \\
\hline Euthymia & & $567(76.5)$ \\
\hline Depression & & $174(23.5)$ \\
\hline Suicide & 744 & \\
\hline Presence of previous attempts, n (\%) & & $209(28.1)$ \\
\hline Psychiatric comorbidity ${ }^{1}, \mathrm{n}(\%)$ & 749 & \\
\hline Any concomitant psychiatric disorder & & $410(54.7)$ \\
\hline $\begin{array}{l}\text { Substance abuse/dependence } \\
\text { disorder }\end{array}$ & & $200(26.7)$ \\
\hline Anxiety disorders & & $119(15.9)$ \\
\hline Personality disorder & & $107(14.3)$ \\
\hline Impulse control disorder & & $65(8.7)$ \\
\hline Eating behavior disorder & & $36(4.8)$ \\
\hline Other disorders & & $28(3.7)$ \\
\hline $\begin{array}{l}\text { High adherence to previous visits } \\
\text { schedule, } \mathrm{n}(\%)\end{array}$ & 743 & $513(69.0)$ \\
\hline $\begin{array}{l}\text { High adherence to previous treatment, } n \\
\text { (\%) }\end{array}$ & 744 & $458(61.6)$ \\
\hline
\end{tabular}


only $32.8 \%$ of patients had been free from symptoms. In this period, $30.9 \%$ of patients had had one episode of mood disorder and $20.2 \%$ two episodes. Of the total sample, $6.5 \%$ met the criteria for rapid cycling (four or more episodes a year). Up to $28.1 \%$ had a previous suicide attempt. Less than $10 \%$ of patients had never been hospitalized from the onset of their disease to the time of inclusion in the study, and $25.6 \%$ had been admitted more than 5 times during this period. From the physician's perspective, up to $31 \%$ of patients had shown low adherence to the previous visit schedule, and up to $38.4 \%$ had shown low adherence to previously prescribed treatments.

Mean total duration of the current manic episode was 76.4 days (SD: 43 ). Prior to the current episode, $76.5 \%$ of patients were in an euthymic state and up to $23.5 \%$ were in a depressed mood state.

The information on resource utilization is shown in Tables 4 . Half of the sample studied required hospitalization, which was in a general hospital in $71.8 \%$ of the cases. The mean length of hospital stay was 22.9 days (SD: 15.5), and bipolar disorder was the primary reason for admission in $93 \%$ of the cases. The mean number of visits to the primary care physician during the episode was 1.9 and 1.6 to the community-based nurse service. The specialist was visited a mean of 5.7 times during the episode. Patients with four or more episodes in the previous year had more lithium determinations ( $1.1 \mathrm{vs.} 2.7 ; \mathrm{p}=0.0003)$, and made more visits to outpatient emergency services ( 0.4 vs. 1.4 ; $\mathrm{p}<0.0001)$ due to their current manic episode. Patients who had never been married $(\mathrm{p}=0.424)$, were from a rural setting $(\mathrm{p}=0.0048)$ and had longer disease duration ( $\mathrm{p}$ for trend $=0.0137$ ) were hospitalized more frequently. Patients who lived alone made more visits to the psychia- trist ( 8.6 vs. 5.3 times, $\mathrm{p}=0.0032$ ). The presence of a history of suicide attempt was associated with a higher number of visits to the psychologist ( 1.1 vs. $0.6, \mathrm{p}=0.02)$, non-psychiatrist specialist $(0.6$ vs. $0.1, \mathrm{p}<0.0001)$ and hospital emergency department ( 1.6 vs. $0.8, \mathrm{p}=0.0005)$. Finally, the absence of psychiatric comorbidity was associated with a higher number of visits to the psychologist. The pharmacological treatment received by patients over the course of their episode consisted of antipsychotics, mood stabilizers and anxiolytics with frequencies of $94.6 \%, 83.9 \%$ and $55.2 \%$, respectively.

The mean total cost of the manic episode in the sample studied was $€ 4,345$. Of this cost, $56 \%$ corresponds to hospitalization, $10 \%$ to specialist care (mainly from psychiatrist visits, with a mean of 6), $14 \%$ to antipsychotics and $15 \%$ to other psychoactive drugs (Figure 1). The direct costs associated with the resources used are shown in Table 5.

\section{Discussion}

This naturalistic study shows that management of a manic episode in the Spanish setting is associated with high healthcare resource utilization, particularly in terms of hospitalization and specialized care in the form of frequent psychiatrist visits. The direct cost associated with healthcare resource utilization is high, with a mean cost of nearly $€ 4,500$ per patient, of which approximately $55 \%$ corresponds to the cost of hospitalization, $30 \%$ to the cost of psychopharmacological treatment and $10 \%$ to the cost of specialized care.

To our knowledge, this is the first study of these characteristics conducted in Spain, so it is not possible for us to put our results in perspective within our setting. The

Table 4: Resource utilization in a cohort of patients with bipolar disorder who had a manic episode: hospitalizations

\begin{tabular}{|c|c|c|}
\hline Characteristics & $\mathbf{N}$ & \\
\hline Required hospitalization, n (\%) & 782 & $391(50)$ \\
\hline Days of hospitalization ${ }^{1}$, mean $\pm S D$ & 383 & $22.9 \pm 15.5$ \\
\hline Cause of hospitalization ${ }^{1}, \mathrm{n}(\%)$ & 389 & \\
\hline Current manic episode ${ }^{2}$ & & $362(93.0)$ \\
\hline Psychiatric comorbidity & & $14(3.6)$ \\
\hline Other causes & & $13(3.4)$ \\
\hline Type of hospital' ${ }^{1}$, n (\%) & 386 & \\
\hline Monographic & & $109(28.2)$ \\
\hline General & & $277(71.8)$ \\
\hline
\end{tabular}

${ }^{1}$ Calculated over the number of evaluable patients who required hospitalization

Includes 4 cases in which the reason for hospitalization was attributed to both the manic episode and the comorbidity

SD: standard deviation; N: number of evaluable cases 


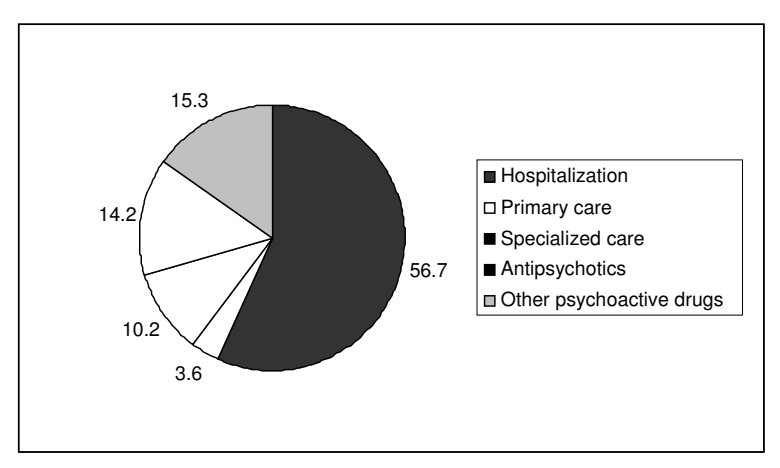

Figure 1 Percent distribution of direct costs associated with the management of a patient with a manic episode $(\mathrm{N}=708)$.

results obtained in the Spanish subsample of 312 patients within the pan-European EMBLEM study, a long-term observational study of acute patients undergoing treatment for mania, have recently been published [24]. Although this subanalysis of the EMBLEM study is very limited with regard to healthcare resource utilization, it does appear to indicate a significant utilization of some healthcare services by these patients in the year prior to inclusion in the study. However, the methodology used, which was limited to the use of a small number of healthcare resources (i.e., hospitalizations and outpatient psychiatric visits) in the year prior to the episode, prevents comparison with our results since they would not correspond to the resource utilization associated with a manic episode.

Very similar to our study in terms of objectives was a study conducted in France that evaluated the direct cost of treatment of manic episodes during a three-month period following hospitalization [20]. The cost, in 1999 values, was much higher than in our study, €22,297 per episode, and $98 \%$ corresponded to hospitalization [20]. At least in Europe, the cost of hospitalization is the most significant portion of the direct costs of bipolar disorder [29], and furthermore, the largest part of these costs of hospitalization is attributable to bipolar I disorder [30]. Therefore, as indicated by the results of Olié \& Lévy's [20] and our study, hospitalization is key in the cost of management of patients with bipolar I disorder and, more specifically, of the manic episode. Irrespective of possible differences in the unit cost per resource, there are several important differences related to hospitalization in the French study that could explain the differences in the cost of the manic episode between the two studies. Only hospitalized patients were included in the French study, whereas in our study, more than $50 \%$ of patients were not hospitalized. Furthermore, the mean duration of hospitalization was 36 days in the French study versus 23 days in our study, and follow-up was for 90 days in the French study versus a mean duration of the episode of 76 days in our study. Although these differences could be attributed to variability in medical practices and resource availability in the two countries, it should be noted that differential diagnosis between mania and hypomania in DSM-IVTR includes use of hospital resources as a diagnostic criterion, which constitutes a peculiarity within the field of medical nosology. In any case, the contribution of hospitalization to the cost of manic episodes is very significant, independent of the geographical area. Thus, costs of hospitalization also account for the largest proportion of the total costs of bipolar disorder in Australia $(70 \%$ of the excess healthcare costs of bipolar disorder are due to hospital admissions) [19] and in the United States, where $36 \%$ of the annual cost of patients with bipolar I disorder is due to hospitalization for privately insured patients [31].

After hospitalization, the next greatest cost in our study is the cost of psychopharmacological treatment (30\% of total cost). The cost of antipsychotic treatment represents $50 \%$ of this pooled cost. The pattern of psychopharmacological treatment in our study, with use of antipsychotics and mood stabilizers in $95 \%$ and $84 \%$ of patients, is practically superimposable on that described in the previously mentioned study of Olié \& Lévy [20] conducted in France. However, the cost of medication in the latter study was a minimal proportion $(0.3 \%)$ of the cost of treatment in the three months following the manic episode. This was probably due to the disproportionate (for the previously explained reasons) importance of hospitalization in this study and the predominant use of conventional antipsychotics. However, in the study of privately insured patients in the United States [31], the cost of psychopharmacological treatment was 13\% of the total cost.

Our study has a number of important limitations. First, convenience sampling was used, so this sample is not representative of patients with a manic episode in Spain. While it is true that the overall demographic and clinical characteristics of the patients in our study are very similar to those of the Spanish sample in the EMBLEM study [24], patients from the rural setting may be underrepresented in both studies.

The problem of lack of representativeness affects most cost studies carried out using a "bottom-up" methodology (activity-based costing method that assess the amount of each resource that is used to produce an individual healthcare service and then assigns costs accordingly to generate aggregate costs for a healthcare system). The main advantage is being able to trace the contribution of each element of an organization to the cost of an individual healthcare service, which allows for better cost management when is particularly relevant for assessing the cost of individual services within complex integrated healthcare systems, as the Spanish one. Additionally, the type of information obtained through a "bottom-up" is 
Table 5: Direct costs associated with the management of a patient with a manic episode $(\mathrm{N}=708)$

\begin{tabular}{|c|c|c|c|}
\hline \multirow[t]{2}{*}{ Resource } & \multirow{2}{*}{$\begin{array}{c}\begin{array}{c}\text { Number of times during } \\
\text { manic episode }\end{array} \\
\text { Mean } \pm S D\end{array}$} & \multicolumn{2}{|c|}{ Cost $(€, 2007)$} \\
\hline & & Mean \pm SD & $95 \% \mathrm{Cl}$ \\
\hline \multicolumn{4}{|l|}{ Hospitalization } \\
\hline Psychiatric hospital stay/day & & $2462 \pm 3424$ & $2210-2715$ \\
\hline \multicolumn{4}{|l|}{ Primary care } \\
\hline Primary care physician visit & $1.9 \pm 6.0$ & $31 \pm 97$ & $24-39$ \\
\hline Nurse visit & $1.6 \pm 4.3$ & $21 \pm 56$ & $17-25$ \\
\hline Lithium determination & $1.3 \pm 3.1$ & $12 \pm 29$ & $10-14$ \\
\hline Group psychotherapy & $0.6 \pm 10.8$ & $25 \pm 454$ & $0-58$ \\
\hline $\begin{array}{l}\text { Outpatient emergency dept. } \\
\text { visit }\end{array}$ & $0.6 \pm 1.8$ & $68 \pm 213$ & $52-84$ \\
\hline
\end{tabular}

Specialized care
$\begin{array}{lccc} \\ \text { Psychiatrist visit } & 5.7 \pm 10.3 & 258 \pm 429 & 227-290 \\ \text { Nonpsychiatric specialist visit } & 0.3 \pm 1.4 & 22 \pm 113 & 14-30 \\ \text { Psychologist visit } & 0.8 \pm 2.4 & 39 \pm 124 & 30-48 \\ \text { Hospital emergency dept. visit } & 1.0 \pm 2.8 & 124 \pm 352 & 98-150\end{array}$

Pharmacological treatment

\begin{tabular}{lccc}
\hline \multicolumn{1}{c}{ Antipsychotics } & 751 (94.6) & $617 \pm 656$ & $569-665$ \\
Other psychoactive drugs ${ }^{1}$ & $\begin{array}{c}\text { Range from 52 } \\
\text { (anticholinergics) to 666 } \\
\text { (mood stabilizers }\end{array}$ & $666 \pm 679$ & $616-716$ \\
& & & $4345 \pm 4019$ \\
\hline Total cost & & $4048-4641$
\end{tabular}

SD: standard deviation; Cl: confidence interval; ${ }^{1}$ Other psychoactive drugs: Includes the cost associated with mood stabilizers, anxiolytics/

hypnotics, antidepressants and anticholinergics.

very relevant for its inclusion in cost-effectiveness modeling studies using combined or cross-national synthesis designs [32]. On the other side, a "top-down" approach (using relative value units, hospitals days, or some other metric to assign total costs for a healthcare system to individual services) could be useful as well in order to assess local cost variation. From our point of view, an utilization of both methods could be advantageous because different methods can serve different purposes, and finally are complementary [33].

The study protocol did not define a standardized method for patient diagnosis, but followed psychiatrist opinion, and this could affect the validity of diagnosis, although we presume that the case of mania could be not as affected as other mental diagnoses. Moreover, for public health decisions the relevant cost of a disease comes from the population considered by the specialists as suffering from the disease.

Also, due to the descriptive retrospective study design, no information can be provided on some predictors of higher cost, such as treatment adherence or persistence on treatment. It has been shown that a better adherence associates with a lower cost in the long term treatment [34].

With regard to the method used for cost allocation, it is important to point out two limitations in our study. First, 
the healthcare costs database used, SOIKOS, has been the standard in Spain for several years. This private database is based on the information gathered from government agency publications, published studies and literature reviews, among others. Its very nature means that the costs provided have not been sufficiently verified or have rapidly become outdated. Second, adjustment of these costs according to inflation is a method that has been questioned on some occasions, a factor that should also be taken into account. Ideally, to overcome these limitations, a single nationwide database, mainly related to public costs as Spain has a public health care system funded by public taxes, would be needed to perform a cost allocation closer to the reality of our healthcare system.

On the other hand, it should be stressed that a more conservative perspective was adopted in this study, and only direct costs were analyzed. No costs were allocated to disease associated mortality, lost productivity, use of the legal or penal system or the associated family burden, in spite of the relative importance of these costs. Regarding the impact of legal problems, reports about the importance of mental health problems in the prison and jail inmates in the USA, estimate that up to $50 \%$ of inmates with mental problems report symptoms of mania [35].

Of the estimated $\$ 45$ billion total cost of bipolar disorder in the United States in 1991 [16], more than 80\% was due to indirect costs, a very similar proportion to that described in another study in the Netherlands [22]. Similarly, of the total excess cost of bipolar disorder in Australia, the largest proportion (85\%) was due to individual expenses; $60 \%$ of these were due to absenteeism from work and 39\% to "presenteeism" (present at work but not functioning efficiently). This large impact on productivity extends beyond the manic episode. In a prospective study six months after discharge that evaluated patients who had been hospitalized after a manic episode, even though $80 \%$ were practically symptom free, only $43 \%$ were employed and only $21 \%$ were working at their expected level of employment [12].

The work disability rate found in our sample is similar to that reported in a study on the employment status of persons with severe chronic mental illnesses based on the national survey on disability conducted in 1999 (20.36\%) [36]. However, the employment rate of the persons with mania included in our study was lower than the employment rate of persons with mental disorders reported in the ESEMeD study in Spain (36.7\%) [37]. Furthermore, access to sheltered employment conditions is considerably lower in patients with bipolar disorder than in other severe mental disorders. In Catalonia, only 7\% of persons in sheltered employment had bipolar disorder, compared to the $62 \%$ with schizophrenia or $8 \%$ with borderline personality disorder (MHEEN-II, 2007). These data indicate that the employment status of persons with bipolar type I disorder requires a specific approach in Spain.

Although it has been pointed that other health economic appraisals can help more policy makers determine the maximum societal benefit that can be achieved, given a finite amount of resources [38], the cost of illness studies are still useful for both clinicians and health authorities to better understand the main sources of cost and identify those aspects that can be subject of interventions and whose efficiency can be analyzed.

\section{Conclusions}

Our study is the first to study resource utilization and costs associated with manic episodes in Spain using a bottom-up approach. Like other studies conducted in Europe and elsewhere, it shows the high cost of management of the patient with a manic episode, which is mainly due to hospitalizations. In this regard, any intervention in the management of the manic patient that reduces the need for hospitalization (e.g., improved preventive pharmacological measures or measures that improve the family or social support of the patient with bipolar disorder) would have a significant impact on the costs of the disease.

\section{Competing interests}

This study was funded by AstraZeneca Farmacéutica Spain in 2005. MT, TD and $\mathrm{LC}$ are full-time employees of AstraZeneca. JS has been a consultant to AstraZeneca, BristolMyers-Squibb, Lilly, GlaxoSmithKline, Lundbeck, Pfizer, Servier, Janssen, and Wyeth; and has received research grants from Lilly, Astra-Zeneca, Janssen, BristolMyers-Squibb and Wyeth. LS had previously been a consultant to Astra-Zeneca, BristolMyers-Squibb, Lilly and Janssen. But during the last three years he has not signed any contract or received research grants from pharmaceutical companies.

\section{Authors' contributions}

All authors participated in the design of the study, the statistical analysis plan and the interpretation of the data. MT conceived of ths study and participated in its coordination. All authors read and approve the final manuscript.

\section{Acknowledgements}

The authors thank Fernando Rico-Villademoros, MD for his contribution in the preparation of a draft of this manuscript

\section{Author Details}

'Medical Department, AstraZeneca, Madrid, Spain, 2PSICOST Scientific Research Association, Cádiz, Spain, ${ }^{3}$ Ramon y Cajal Hospital and University of Alcalá, Madrid, Spain and ${ }^{4}$ Columbia University, Department of Psychiatry, New York, USA

Received: 6 August 2009 Accepted: 28 April 2010

Published: 28 April 2010

References

1. American Psychiatric Association: Practice guideline for the treatment of patients with bipolar disorder (revision). Am J Psychiatry 2002, 159(4 Suppl): $1-50$

2. American Psychiatric Association: Diagnostic and Statistical Manual of Mental Disorders, Fourth Edition (text revision). Washington, DC, APA 2000. 
3. Wittchen HU, Jacobi F: Size and burden of mental disorders in Europe--a critical review and appraisal of 27 studies. Eur Neuropsychopharmacol 2005, 15:357-76.

4. Criado-Alvarez JJ, Domper Tornil JA, de la Rosa Rodriguez G: Estimación de la prevalencia de trastornos bipolares tipo I en España a través del consumo de carbonato de litio. Rev Esp Salud Publica 2000, 74:131-8.

5. Murray CJL, Lopez AD, eds: The Global Burden of Disease and Injury Series, Volume 1: A Comprehensive Assessment of Mortality and Disability from Diseases, Injuries, and Risk Factors in 1990 and Projected to 2020. Cambridge, Mass: Published by the Harvard School of Public Health on behalf of the World Health Organization and the World Bank; Harvard University Press; 1996.

6. Prince M, Patel V, Saxena S, Maj M, Maselko J, Phillips MR, Rahman A: No health without mental health. Lancet 2007, 370:859-77.

7. Pini S, de Queiroz V, Pagnin D, Pezawas L, Angst J, Cassano GB, Wittchen $\mathrm{HU}$ : Prevalence and burden of bipolar disorders in European countries. Eur Neuropsychopharmacol 2005, 15:425-34.

8. Harris E, Barraclough B: Suicide as an outcome for mental disorders. A meta-analysis. BrJ Psychiatry 1997, 170:205-228.

9. Sharma R, Markar H: Mortality in affective disorder. J Affect Disord 1994, 31:91-6.

10. Osby U, Brandt L, Correia N, Ekbom A, Sparen P: Excess mortality in bipolar and unipolar disorder in Sweden. Arch Gen Psychiatry 2001, 58:844-50.

11. Keck PE Jr, McElroy SL, Strakowski SM, West SA, Sax KW, Hawkins JM, Bourne ML, Haggard P: 12-month outcome of patients with bipolar disorder following hospitalization for a manic or mixed episode. Am J Psychiatry 1998, 155:646-52.

12. Dion GL, Tohen M, Anthony WA, Waternaux CS: Symptoms and functioning of patients with bipolar disorder six months after hospitalization. Hosp Community Psychiatry 1988, 39:652-7.

13. Leidy NK, Palmer C, Murray M, Robb J, Revicki DA: Health-related quality of life assessment in euthymic and depressed patients with bipolar disorder. Psychometric performance of four self-report measures. Affect Disord 1998, 48:207-14.

14. Dean BB, Gerner D, Gerner RH: A Systematic Review Evaluating HealthRelated Quality of Life, Work Impairment, and Healthcare Costs and Utilization in Bipolar Disorder. Curr Med Res Opin 2004, 20:139-154.

15. Andlin-Sobocki $P$, Wittchen HU: Cost of affective disorders in Europe. European Journal of Neurology 2005, 12(S1):34-8.

16. Wyatt RJ, Henter I: An economic evaluation of manic-depressive illness-1991. Soc Psychiatry Psychiatr Epidemiol 1995, 30:213-9.

17. Begley CE, Annegers JF, Swann AC, Lewis C, Coan S, Schnapp WB, BryantComstock L: The lifetime cost of bipolar disorder in the US: an estimate for new cases in 1998. Pharmacoeconomics 2001, 19(5 Pt 1):483-95.

18. Guo JJ, Keck PE, Li H, Jang R, Kelton CML: Treatment Costs and Health Care Utilization for Patients with Bipolar Disorder in a Large Managed Care Population. Value Health 2008, 11:416-23.

19. Fisher LJ, Goldney RD, Grande ED, Taylor AW, Hawthorne G: Bipolar disorders in Australia: A population-based study of excess costs. Soc Psychiatry Psychiatr Epidemiol 2007, 42:105-9.

20. Olie JP, Levy E: Manic episodes: the direct cost of a three-month period following hospitalisation. Eur Psychiatry 2002, 17:278-86.

21. de Zelicourt M, Dardennes R, Verdoux H, Gandhi G, Khoshnood B, Chomette E, Papatheodorou ML, Edgell ET, Even C, Fagnani F: Frequency of hospitalisations and inpatient care costs of manic episodes: in patients with bipolar I disorder in France. Pharmacoeconomics 2003 21:1081-90.

22. Hakkaart-van Roijen L, Hoeijenbos MB, Regeer EJ, ten Have M, Nolen WA, Veraart CP, Rutten FF: The societal costs and quality of life of patients suffering from bipolar disorder in the Netherlands. Acta Psychiatr Scand 2004, 110:383-92.

23. Das Gupta R, Guest JF: Annual cost of bipolar disorder to UK society. Br J Psychiatry 2002, 180:227-33.

24. Montoya A, Gilaberte I, Costi M, Perez Sanchez Toledo J, Gonzalez Pinto A, Ma Haro J, Comes M, Vieta E: El trastorno bipolar en España: estado funcional y consumo de recursos según la muestra española del estudio observacional paneuropeo EMBLEM. Vertex 2007, 18:13-9.

25. Andlin-Sobocki $\mathrm{P}$, Jonsson B, Wittchen $\mathrm{H}-\mathrm{U}$ : Cost of disorders of the brain in Europe European. Journal of Neurology 2005, 12(S1):1-27.
26. Gisbert R, Brosa M: Base de Datos de Costes Sanitarios 1997-2004 [CDROM] Versión 1.6. Barcelona: Centro de Estudios en Economía de la Salud y Política Social; 2004.

27. Instituto Nacional de Estadística: Índice de precios de consumo: ¿Cuánto ha variado el IPC desde...? [on line]. [http://www.ine.es/cgi-bin/certi]. [Access date: March 2007]

28. Base de Datos del Medicamento [internet data base]. Madrid: Consejo General de Colegios Oficiales de Farmacéuticos [http:// botplusweb.portalfarma.com/

29. Kleinman L, Lowin A, Flood E, Gandhi G, Edgell E, Revicki D: Costs of bipolar disorder. Pharmacoeconomics 2003, 21:601-22.

30. Stender M, Bryant-Comstock L, Phillips S: Medical resource use among patients treated for bipolar disorder: a retrospective, cross-sectional, descriptive analysis. Clin Ther 2002, 24:1668-76.

31. Bryant-Comstock L, Stender M, Devercelli G: Health care utilization and costs among privately insured patients with bipolar I disorder. Bipolar Disord 2002, 4:398-405.

32. Evers $S$, Salvador-Carulla L, Halsteinli V, McDaid D, the MHEEN group: Implementing mental health economic evaluation evidence: Building a bridge between theory and practice. Journal of Mental Health 2007, 16:223-241

33. Chapko MK, Liu CH, Perkins M, Li YF, Fortney JC, Maciejewski ML: Equivalence of two healthcare costing methods: Bottom-up and topdown. Health Econ 2008, 18:1188-201.

34. Revicki DA, Hirschfeld RM, Ahearn EP, Weisler RH, Palmer C, Keck PE Jr: Effectiveness and medical costs of divalproex versus lithium in the treatment of bipolar disorder: results of a naturalistic clinical trial. $J$ Affect Disord 2005, 86(2-3):183-93.

35. Bridget M: Kuehn Mental Health Courts Show Promise. JAMA 2007, 297:1641-1643.

36. Instituto Nacional de Estadística (INE): Encuesta de Población Activa (E.P.A.) Módulo año 2002: Personas con discapacidad y su relación con el empleo. [on line]. [http://www.ine.es/jaxi/ menu.do?type $=$ pcaxis\&path $=/$ t22/e308/meto 05/modulo/2002/ \&file=pcaxis].

37. Mental Health Economics European Network (MHEEN-II): Mental Health and Employment Questionnaire: Spain. Project Report; 2007.

38. Currie G, Kerfoot K D, Donaldson C, Macarthur C: Are cost of injury studies useful? Injury Prevention 2000, 6:175-176.

Pre-publication history

The pre-publication history for this paper can be accessed here: http://www.biomedcentral.com/1471-244X/10/31/prepub

\section{doi: 10.1186/1471-244X-10-31}

Cite this article as: Tafalla et al., Pattern of healthcare resource utilization and direct costs associated with manic episodes in Spain BMC Psychiatry 2010, 10:31

\section{Submit your next manuscript to BioMed Central and take full advantage of:}

- Convenient online submission

- Thorough peer review

- No space constraints or color figure charges

- Immediate publication on acceptance

- Inclusion in PubMed, CAS, Scopus and Google Scholar

- Research which is freely available for redistribution 